\title{
CORRECTION
}

\section{Correction to: Factors influencing the results of surgical therapy of non-acute subdural haematomas}

\author{
René Opšenák ${ }^{1} \cdot$ Martin Hanko ${ }^{1} \cdot$ Pavol Snopko ${ }^{1} \cdot$ Kristián Varga $^{1} \cdot$ Tomáš Fejerčák $^{1} \cdot$ Branislav Kolarovszki $^{1}$
}

Published online: 18 November 2019

๑) Springer-Verlag GmbH Germany, part of Springer Nature 2019

\section{Correction to: \\ European Journal of Trauma and Emergency Surgery https://doi.org/10.1007/s00068-019-01258-3}

The original version of this article unfortunately contained some mistakes. The sequence of the author names was incorrect. The correct information is given above.

The original article can be found online at https://doi.org/10.1007/ s00068-019-01258-3.

Branislav Kolarovszki

branislav.kolarovszki@jfmed.uniba.sk

1 Clinic of Neurosurgery, Jessenius Faculty of Medicine in Martin, Comenius University in Bratislava, University Hospital Martin, Kollarova 2, 03659 Martin, Slovakia 